\title{
SOME EXPERIMENTAL STUDIES ON PLASMA CUTTING QUALITY OF LOW ALLOY STEEL
}

\author{
BEGIC, D[erzija]; KULENOVIC, M[alik]; CEKIC, A[hmet] \& DEDIC, E[Idin]
}

\begin{abstract}
This paper presents an experimental study to evaluate the effect of the cutting parameters on the cut quality during plasma cutting of $5 \mathrm{~mm}$ thick low alloy steel sheets. The cutting parameters considered include cutting speed and plasma gas pressure. The CNC portal cutting machine VARCUT L2 by plasma device type D12000 is used in the experiments. Results show that good quality cuts can be produced in plasma cutting of low alloy steel, at the cutting speed from 400 to $700 \mathrm{~mm} / \mathrm{min}$ and at the plasma gas pressure from 4 to $5 \mathrm{bar}$.
\end{abstract}

Keywords: plasma cutting, low alloy steel, cutting parameters, cut quality

\section{INTRODUCTION}

When the temperature of a gas is raised to about $2000 \tilde{C}$, the gas molecules become dissociated into

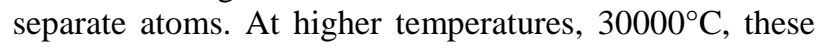
atoms become ionized. The gas in this stage is termed plasma. Plasma cutting process is a thermal nontraditional machining process that was adopted in the early 1950s as an alternative method for flame cutting of stainless steel, aluminum, and other nonferrous metals. During that time the process limitations regarding the low cutting speed, poor machining quality, and the unreliable equipment were clear. Recently, cutting of conductive and nonconductive materials by plasma cutting has become much more attractive [1]. In the machine manufacturing industry, the plasma, as a tool, is used especialy in cutting operations, coating, welding, melting, and assistance of the mechanical processing operations such as turning, threading, drilling, grooving etc., in order to improve the machinability of various materials. This process has been used in cutting applications of stainless steel, hardened and high melting-point metal and hardened alloys [2]-[5].

The cutting accuracy depends on material thickness and even more on the used thermal cutting procedure. The biggest deviations appear by flame cutting, which is usually used for cutting thicker materials with lower speed. On the other hand, the lowest deviations appear by laser cutting, which is usually used for cutting thinner materials with increased cutting speed. Reference [6] also shown that laser beam machines offer more accuracy and precision, but plasma cutting machines have a significant advantage over laser machines in terms of acquisition cost, maintenance and productivity. However, both laser and plasma arc cutting machines offers good results depending on the type of material being cut and of the results needed.

Of particular interest to manufacturers using plasma cutting process are the productivity and the quality of components made by plasma cutting. Both aspects are managed by the selection of appropriate cutting parameters, which are unique for each material and thickness. Consequently, investigation into the affecting parameters in plasma cutting process is necessary to improve the final product quality. To reduce the kerf width and to improve the kerf quality, the hydromagnetically confined plasma arc is used to cut engineering ceramic plates [7].

They have shown that when the nozzle diameter is 3 $\mathrm{mm}$, the kerf width of the examined ceramic plate of 6 $\mathrm{mm}$ thickness is less than $4.6 \mathrm{~mm}$, while the cutting speed reaches to $0.9-1.2 \mathrm{~m} / \mathrm{min}$. A $5 \mathrm{~mm}$ thick sheet of grade 2 commercially pure titanium was cut using several feed rates in the dross free feed rate range and with the adoption of oxygen or nitrogen as cutting and shielding gases [8]. It shown that when oxygen is used as cutting gas higher feed rate and geometry attributes (unevenness and kerf width) of better quality are achieved due to the oxidation reaction. The thickness of the total heat affected zone overcame $1 \mathrm{~mm}$ for all the cuts in nitrogen and for the slowest cut in oxygen. In [9], AISI 304 stainless steel and St 52 carbon steel have been cut by plasma arc and the variations of structural specifications occurred after cutting has been investigated. According to the experimental results, it has been seen that burning of particulars and distribution amount are increased when the cutting is performed using the speeds which are upper or lower limits of the ideal cutting speeds proposed by the manufacturer of the machine tool. In [10] a $200 \mathrm{~A}$ high tolerance plasma arc cutting system is utilized to cut plates from $15 \mathrm{~mm}$ thick mild steel sheets metals. The performed analysis indicates that cutting speed and arc voltage affect the kerf formation mechanism and their interaction is also important in defining the inclination of the cut.

The aim of this paper is to study the effect of the cutting parameters such as cutting speed and plasma gas pressure on kerf width and surface roughness in plasma cutting of low alloy steel, and hence obtain the optimum ranges of cutting speed and plasma gas pressure.

\section{EXPERIMENTAL SETUP}

In order to achieve the stated objective, plasma cutting experiments are carried out using $5 \mathrm{~mm}$ low alloy steel sheets to investigate the effect of plasma cutting parameters on the cut quality. Experimental investigations were conducted in óSirbegovic Groupô company. 


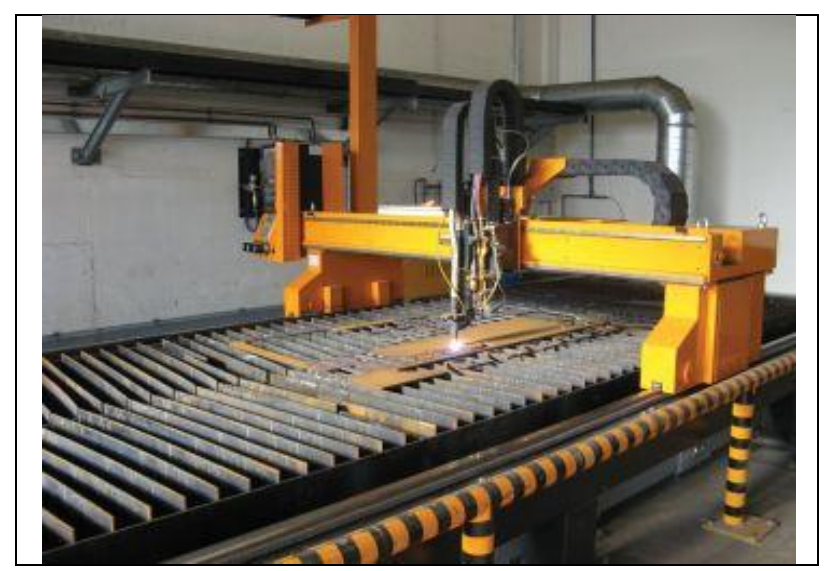

Fig. 1. CNC portal cutting machine VARCUT L2

The CNC portal cutting machine VARCUT L2 by plasma device D-12000 is used in the experiments. The CNC portal cutting machines VARCUT L2 are very precise and reliable. The portal cutting machine has one head for plasma sheet metal cutting and one head for flame cutting of sheet metal with a dual side longitudinal drive with AC motors. The construction of the cutting machine with the support table allows a maximum cutting thickness of $150 \mathrm{~mm}$ [11].

Two main parameters have been selected for the present study. These are cutting speed and plasma gas pressure. These parameters are varied within the range:

1. the cutting speed from $200 \mathrm{~mm} / \mathrm{min}$ to $1000 \mathrm{~mm} / \mathrm{min}$, and

2. the plasma gas pressure from 3 to 5 bar.

Testing the effect of one parameter on the cut quality requires the variation of one parameter while keeping the second parameter at the pre-selected value. The stand off distance of $10 \mathrm{~mm}$ and the current intensity of $30 \mathrm{~A}$ during the execution of experiments are kept constant.

Chemical composition of the examined material is given in table 1 .

\begin{tabular}{|c|c|c|c|c|c|c|c|}
\hline \multicolumn{7}{|c|}{ Material: EN 10025 } \\
\hline $\mathrm{C}$ & $S i$ & $M n$ & $C r$ & $S$ & $P$ & $C u$ & $N i$ \\
\hline 0.17 & 0.35 & 0.60 & 0.15 & 0.035 & 0.05 & 0.08 & 0.02 \\
\hline
\end{tabular}

Tab. 1. Chemical composition of examined material

The controlled parameters have been the top surface kerf width and the surface roughness. A visual inspection of each cut was carried out to ensure that no pitting and burrs are present in the cut area. Figure shows the cut sample of the measurements taken.

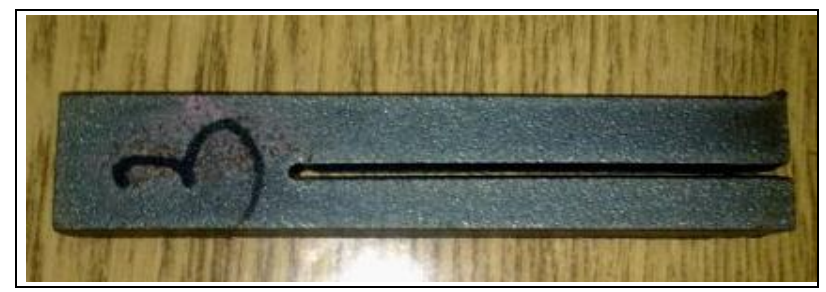

Fig. 2. The geometry of cut samples
Surface roughness on the cut edge was measured in terms of the average roughness $R a$, using the SurfTest Mitutoyo stylus instrument, figure 3. Roughness was measured along the length of cut at approximately the middle of the thickness.

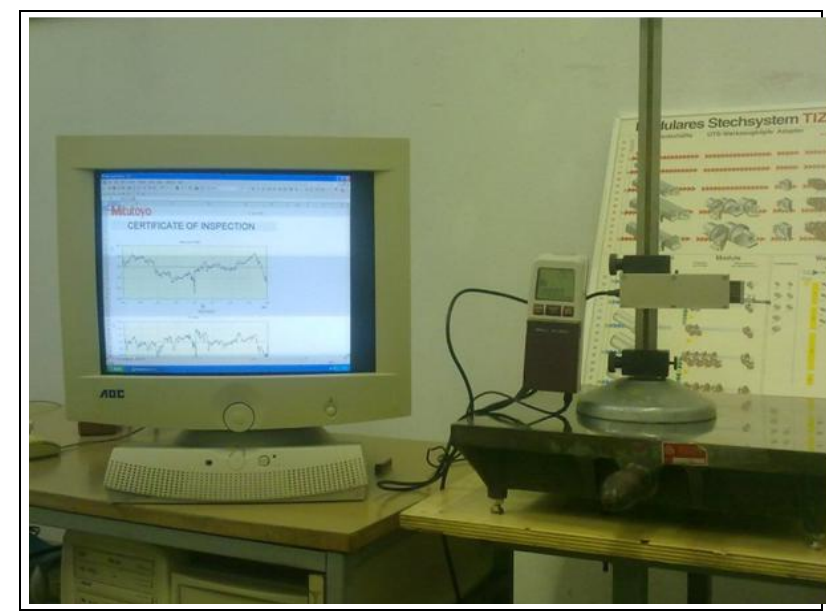

Fig. 3. The roughness measurement using the Mitutoyo stylus instrument

The top surface kerf width was measured using a ZKM universal two-coordinate microscope, figure 4. The cut samples after plasma cutting low alloy steel with varying the cutting speed and the plasma gas preassure is given in figure 5 .

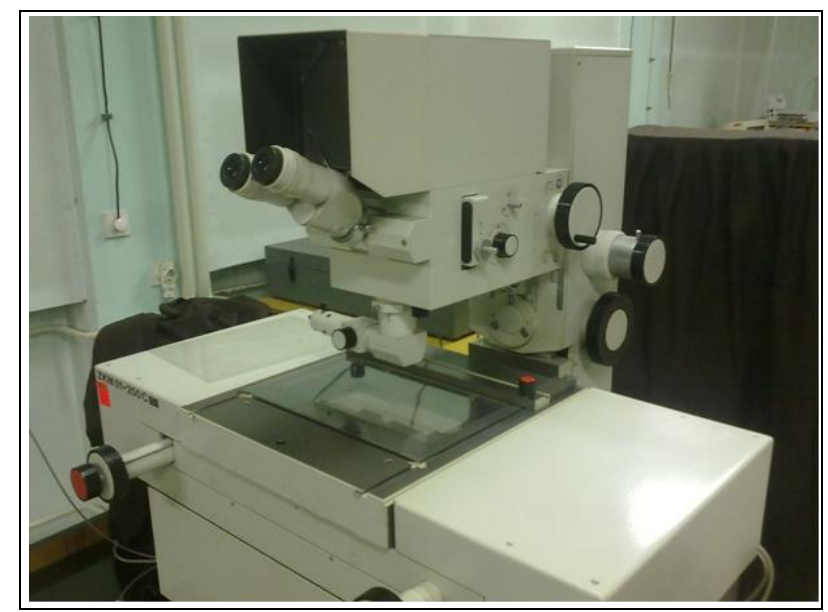

Fig. 4. The measuring of kerf width using ZKM universal twocoordinate microscope

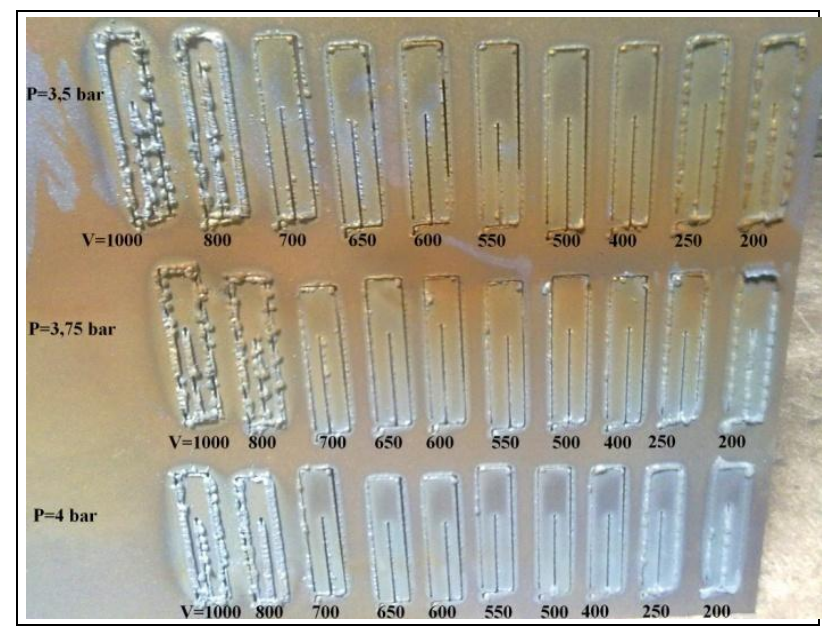

Fig. 5. The cut samples after plasma cutting low alloy steel with varying the cutting speed and the plasma gas preassure 


\section{RESULTS AND DISCUSSION}

The effect of cutting speed on the surface roughness and the kerf width at different plasma gas pressures of 3, $3.5,4$ and 5 bar is shown in figures $6,7,8$ and 9, respectively.

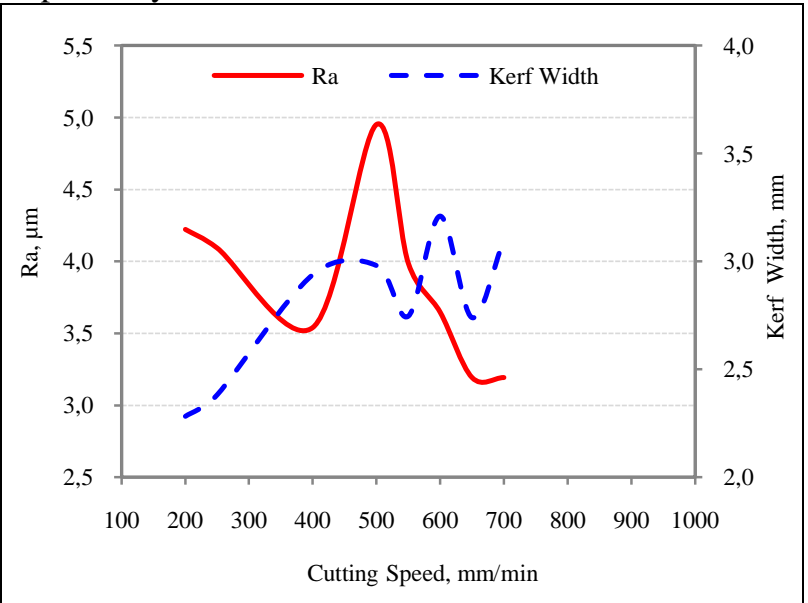

Fig. 6. The effect of cutting speed on surface roughness and the kerf width at a constant plasma gas pressure of 3 bar

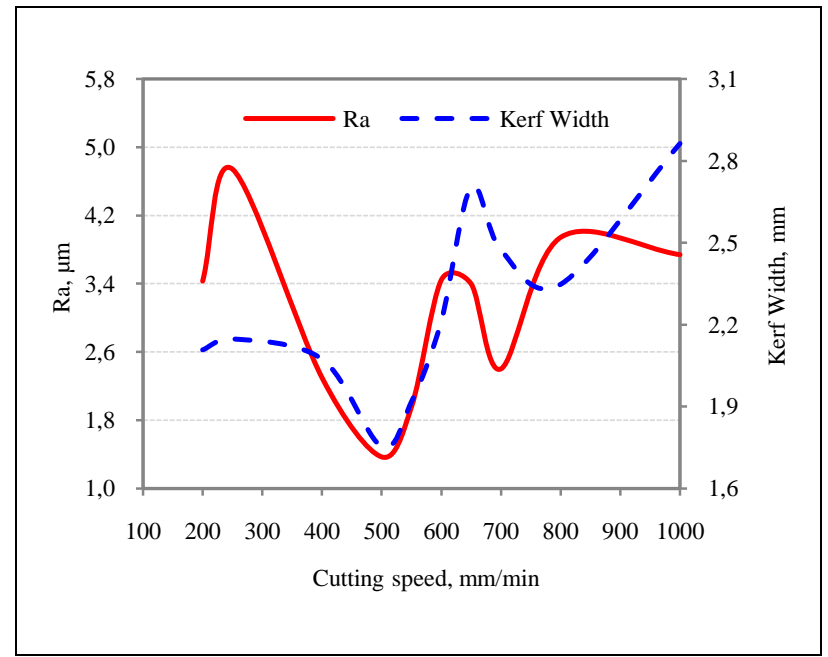

Fig. 7. The effect of cutting speed on surface roughness and the kerf width at a constant plasma gas pressure of $3.5 \mathrm{bar}$

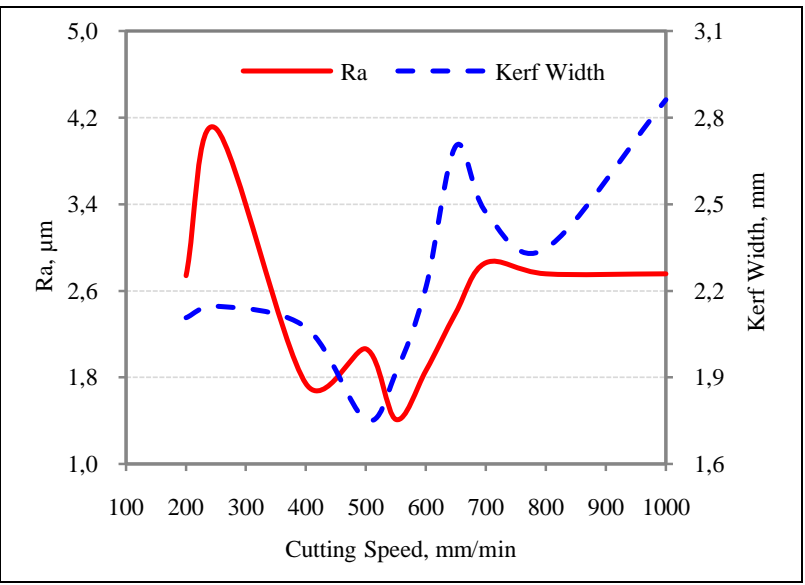

Fig. 8. The effect of cutting speed on surface roughness and the kerf width at a constant plasma gas pressure of 4 bar

As shown in the diagrams in figures 6,7 and 8 , can be concluded that kerf width increases by increasing cutting speed.

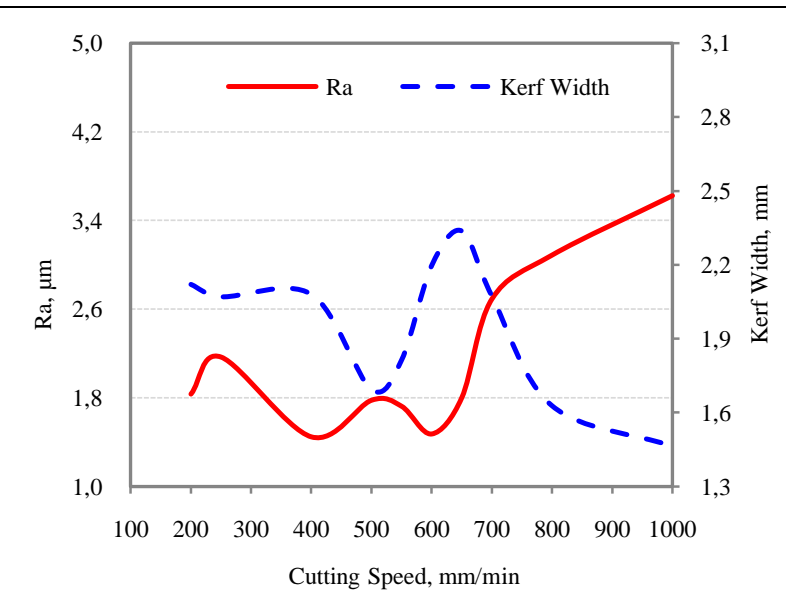

Fig. 9. The effect of cutting speed on surface roughness and the kerf width at a constant plasma gas pressure of 5 bar

At the plasma gas pressure of 5 bar, in figure 9, can be seen that kerf width increases by increasing cutting speed up to $650 \mathrm{~mm} / \mathrm{min}$, but further increase in cutting speed the kerf width decreases. In some cases, for a given cutting speed (in the range of 400 to $700 \mathrm{~mm} / \mathrm{min}$ ), the roughness parameter $R a$ retains approximately constant value or slightly increases. At a plasma gas pressure of 3 bar for the same cutting speed, figures 10 and 11, surface roughness and kerf width are greater than the plasma gas pressure of 5 bar.

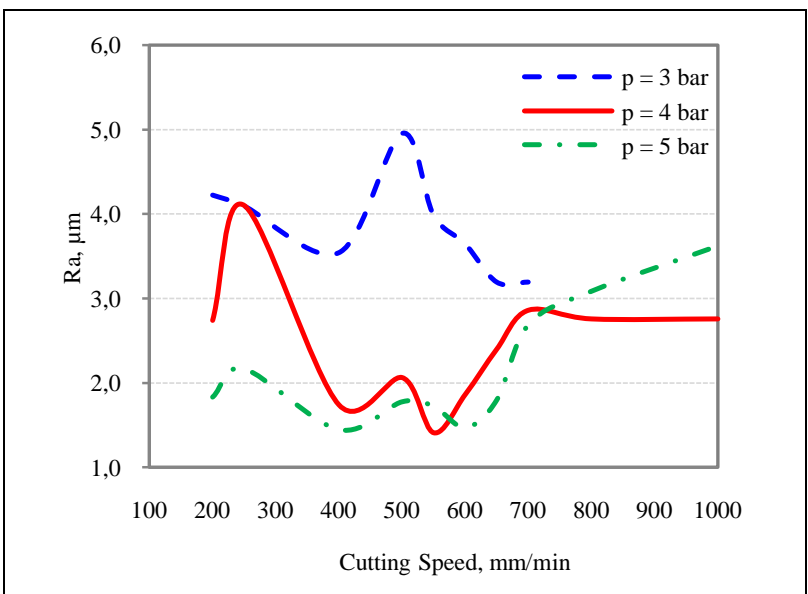

Fig. 10. The effect of the plasma gas pressure on surface roughness by varying the cutting speed

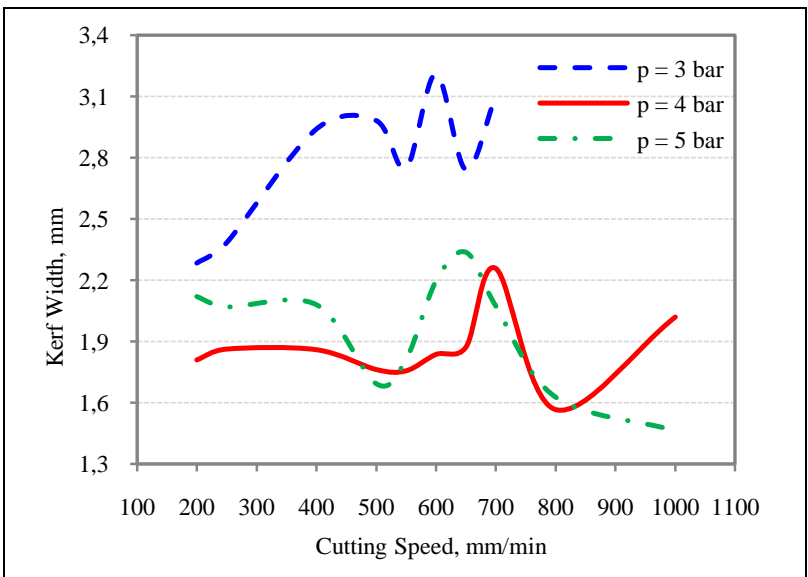

Fig. 11. The effect of the plasma gas pressure on kerf width by varying the cutting speed 


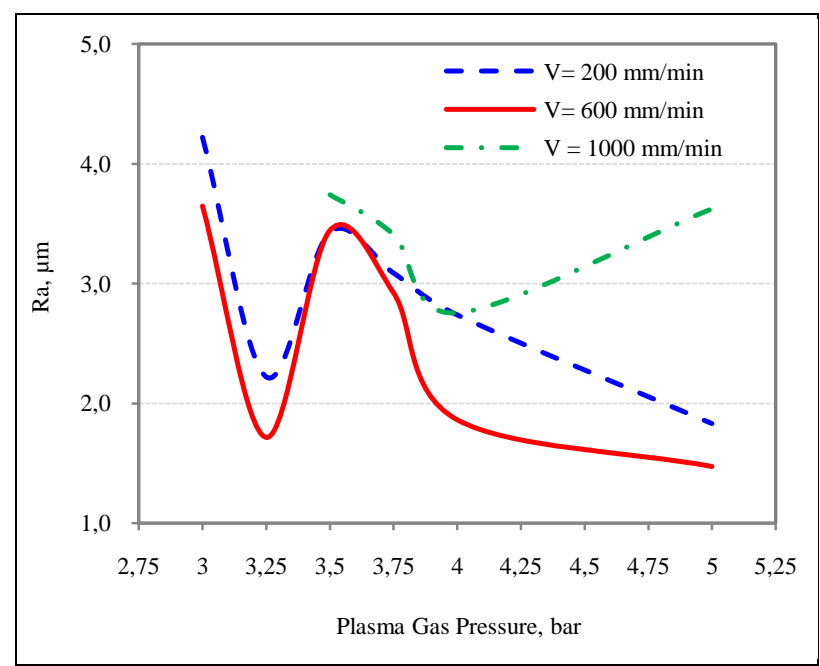

Fig. 12. The effect of cutting speed on surface roughness by varying the plasma gas pressure

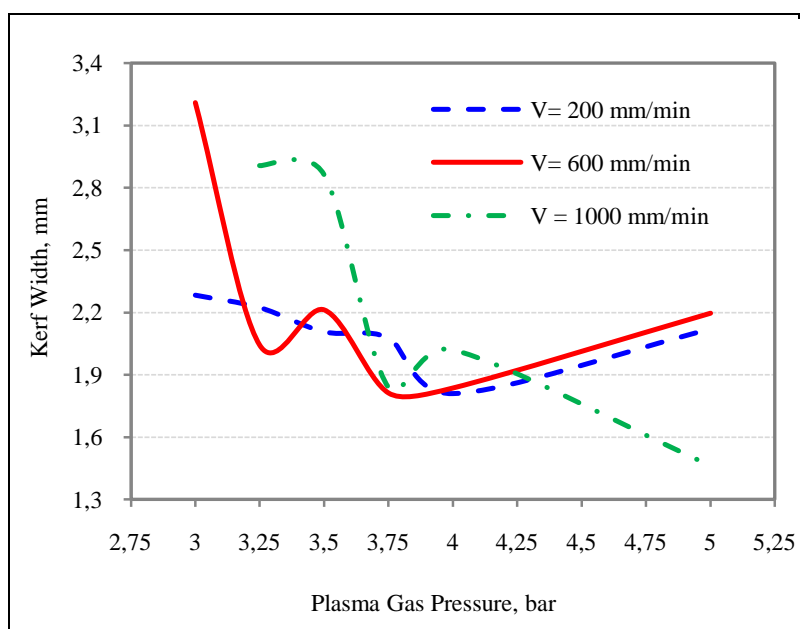

Fig. 13. The effect of cutting speed on kerf width by varying the plasma gas pressure

It was not possible to cut at a plasma gas pressure of 3 bar and the cutting speeds higher than $700 \mathrm{~mm} / \mathrm{min}$, as shown in figures 10 and 11.

In the diagrams shown in figures 12 and 13, it can be concluded that surface roughness and kerf width decrease by increasing plasma gas pressure. It can be noted that the cutting was not possible at the cutting speed of 1000 $\mathrm{mm} / \mathrm{min}$ and a pressure less than $3.5 \mathrm{bar}$. It can further be seen that at cutting speeds of 200 and $600 \mathrm{~mm} / \mathrm{min}$, kerf width and surface roughness slightly changed at the same plasma gas pressure, while the surface roughness increases at cutting speed of $1000 \mathrm{~mm} / \mathrm{min}$. The obtained minimum and maximum value of the roughness parameter $R a$ were $1,410^{-} \mathrm{m}$ and $4,953^{-} \mathrm{m}$. The obtained values of parameter $R a$ belong to the roughness class of N6 and N8, respectively. This fact indicates the importance of research and analysis of the effect of cutting speed and plasma gas pressure on the cut quality.

\section{CONCLUSION}

The effect of cutting speed and plasma gas pressure on the quality characteristics of plasma cut low alloy steel specimens studied in this paper. Based on the conducted investigations, the following could be concluded:
- Kerf width decreases with increasing plasma gas pressure, while it slightly changes with increasing cutting speed.

- Surface roughness decreases by increasing plasma gas pressure and changes very slightly with increasing cutting speed.

- The dross on the bottom side of workpieces increases by increasing cutting speed.

- The cutting of examined material was not possible at a plasma gas pressure of 3 bar and the cutting speed greater than $700 \mathrm{~mm} / \mathrm{min}$.

- Based on the above conclusions, for plasma cutting of low alloy steel sheets of $5 \mathrm{~mm}$ thick, it is recommended to use the cutting speed of 400 $\mathrm{mm} / \mathrm{min}$ to $700 \mathrm{~mm} / \mathrm{min}$ and plasma gas pressure of 4 to 5 bar.

Effect of arc voltage and stand off distance on the cut quality in plasma cutting of low alloy steel, it is recommended to further investigations and a comparsion with laser cut quality.

\section{ACKNOWLEDGEMENTS}

The authors would like to thank óSirbegovic Groupô company for its support throughout the experiments.

\section{REFERENCES}

[1] Helmi, A. Y. \& Hassan, El-H. (2008). Machining Technology: Machine Tools and Operations, CRC Press, ISBN: 978-1-42004339-6, Egypt

[2] Lucas, W. \& Rennie, S. (1993). Cutting procesess the right choice ñ part 1. Welding and Metal Fabrication, Vol. 61, Issue 3, April 1993, pp. 122-127

[3] Willett, K. (1996). Cutting options for the modern fabricator Weld and Metal Fabrication, Vol. 64, Issue 5, May 1995, pp.186188

[4] Ian, S. (1997). Plasma arc cutting takes a slice at competition. Welding and Metal Fabrication, Vol. 65, Issue 7, 1997, pp. 16-19

[5] Bhuvenesh, R.; Norizaman, M.H. \& Abdul Manan, M.S. (2012). Surface roughness and MRR effect on manual plasma arc cutting machining. World Academy of Science, Engineering and technology, Vol. 62, February 2012, pp. 503-506

[6] Ilii, S. \& Munteanu, A. (2008). Comparsion between plasma arc cutting and laser cutting, Proceedings of the $19^{\text {th }}$ International DAAAM Symposium, 22-25 ${ }^{\text {th }}$ October, Trnava, ISSN 1726-9679, ISBN 978-3-901509-68-1, Katalinic, B. (Ed.), pp. 0629-0630, Published by DAAAM International, Vienna

[7] Xu, W.J.; Fang, J.C. \& Lu, Y.S. (2002). Study on ceramic cutting by plasma arc. Juornal of Materials Processing Technology, Vol.129, 1-3, October 2002, pp.152-156, ISSN: 0924-0136

[8] Gariboldi, E. \& Previtali, B. (2005). High tolerance plasma arc cutting of commercially pure titanium. Journal of Materials Processing Technology, Vol.160, 1, March 2005, pp.77-89, ISSN: 0924-0136

[9] Abdulkadir, G. \& Umut, A. (2006). Investigation of the effects of plasma arc parameters on the structure variation of AISI 304 and St 52 steel. Materials \& Design, Vol.27, 10, 2006, pp.1157-1162, ISSN: 0261-3069

[10] Bini, R.; Colosimo, B.M.; Kutlu, A.E. \& Monno, M. (2008) Experimental study of the features of the kerf generated by a 200 A high tolerance plasma arc cutting system. Journal of Materials Processing Technology, Vol.196, 1-3, January 2008, pp.345-355, ISSN: 0924-0136

[11] http://www.varstroj.si, (2010). Katalog_2010_TRK_ANG, Accessed on: 2012-06-25 